\title{
Fever of unknown origin
}

\author{
Authors: Catharina Mulders-Manders, ${ }^{A}$ Anna Simon ${ }^{B}$ and Chantal Bleeker-Rovers ${ }^{C}$
}

\begin{abstract}
More than 50 years after the first definition of fever of unknown origin (FUO), it still remains a diagnostic challenge. Evaluation starts with the identification of potential diagnostic clues (PDCs), which should guide further investigations. In the absence of PDCs a standardised diagnostic protocol should be followed with PET-CT as the imaging technique of first choice. Even with a standardised protocol, in a large proportion of patients from western countries the cause for FUO cannot be identified. The treatment of FUO is guided by the final diagnosis, but when no cause is found, antipyretic drugs can be prescribed. Corticosteroids should be avoided in the absence of a diagnosis, especially at an early stage. The prognosis of FUO is determined by the underlying cause. The majority of patients with unexplained FUO will eventually show spontaneous remission of fever. We describe the definition, diagnostic workup, causes and treatment of FUO.
\end{abstract}

\section{Definition and causes}

Fever of unknown origin (FUO) was first defined by Petersdorf and Beeson in 1961, who defined FUO as body temperature above $38.3^{\circ} \mathrm{C}\left(101^{\circ} \mathrm{F}\right)$ on three or more occasions and a duration of illness of at least three weeks, in which no diagnosis was made after one week of hospital admission. ${ }^{1}$ In the following years this definition was modified. Immunocompromised patients are now excluded, ${ }^{2}$ as these patients have other etiologies of FUO and need a different therapeutic approach. To reflect the increasing outpatient-based healthcare it was suggested to shorten the duration of investigation to three inpatient days or three outpatient visits. ${ }^{2}$ However, as investigations in three outpatient visits and three inpatient days cannot be compared, different causes of FUO will be found in admitted patients. Instead of using arbitrary quantitative time criteria, a quantitative criterion of obligatory investigations was implemented in the definition. ${ }^{3-5}$ The current definition of FUO is:

Authors: Ainternal medicine resident, PhD student, Department of Internal Medicine, Radboud University Nijmegen Medical Center, Nijmegen, The Netherlands; Binternist-infectious disease specialist, Department of Internal Medicine, Radboud University Nijmegen Medical Center, Nijmegen, The Netherlands; Cinternist-infectious disease specialist, Department of Internal Medicine, Radboud University Nijmegen Medical Center, Nijmegen, The Netherlands
$>$ temperature $\geq 38.3^{\circ} \mathrm{C}\left(101^{\circ} \mathrm{F}\right)$ on at least two occasions

$>$ duration of illness $\geq 3$ weeks or multiple febrile episodes in $\geq 3$ weeks

$>$ not immunocompromised (neutropenia for $\geq 1$ week in the 3 months prior to the start of the fever; known HIVinfection; known hypogammaglobulinemia or use of $10 \mathrm{mg}$ prednisone or equivalent for $\geq 2$ weeks in the 3 months prior to the start of the fever)

> Diagnosis uncertain despite thorough history-taking, physical examination and the following investigations: erythrocyte sedimentation rate or C-reactive protein, haemoglobin, platelet count, leukocyte count and differentiation, electrolytes, creatinine, total protein, protein electrophoresis, alkaline phosphatase, aspartate aminotransferase, alanine aminotransferase, lactate dehydrogenase, creatine kinase, antinuclear antibodies, rheumatoid factor, microscopic urinalysis, ferritin, three blood cultures, urine culture, chest X-ray, abdominal ultrasonography and tuberculin skin test.

Over 200 causes of FUO have been described in the literature. These causes can be subdivided in four categories: infections, malignancies, non-infectious inflammatory diseases (NIID, this group includes autoimmune and rheumatic diseases, vasculitis syndromes and granulomatous disorders) and miscellaneous causes. ${ }^{3,6}$ Overall, uncommon presentations of common diseases account for most cases.

In developing countries, infections are the major cause of $\mathrm{FUO}^{7-14}$, whereas in developed countries NIID account for most cases. ${ }^{15-18}$ In several recent studies no cause could be found in a large proportion of patients (Table 1)..$^{3,5,19-21}$ Lower incidences of specific infections, such as tuberculosis and brucellosis, and differences in availability of modern imaging techniques, such as CT, MRI and FDG-PET/CT, may among others cause these differences.

\section{Investigating FUO}

Prior to any additional investigation, manipulation of the thermometer needs to be excluded. Further diagnostic evaluation of FUO starts with the identification of potential diagnostic clues (PDCs). ${ }^{3-5,22}$ PDCs are defined as all signs, symptoms and abnormalities pointing towards a possible diagnosis. PDCs are identified by complete and repeated history taking. The history should include information on previous medical history, drug use, family history, travel history, sexual history, unusual exposure due to occupation or hobbies, and animal contacts. The search for PDCs is further carried out by a 
Table 1. Characteristics and outcome of cohort studies on the etiology of FUO ( $\geq 100$ patients published in the last 10 years or from Western Europe).

\begin{tabular}{|c|c|c|c|c|c|c|c|c|c|c|}
\hline \multirow{2}{*}{$\begin{array}{l}\text { Study and year } \\
\text { of publication }\end{array}$} & \multicolumn{5}{|c|}{ Study characteristics } & \multicolumn{5}{|c|}{ Cause of FUO (\% of total number of cases) } \\
\hline & Country & $\begin{array}{l}\text { Hospital } \\
\text { type }\end{array}$ & $\begin{array}{l}\text { Inclusion } \\
\text { period }\end{array}$ & Design & $\begin{array}{l}\text { Patients, } \\
\mathrm{n}\end{array}$ & $\begin{array}{l}\text { Infec- } \\
\text { tion }\end{array}$ & $\begin{array}{l}\text { Malig- } \\
\text { nancy }\end{array}$ & NIID $^{a}$ & $\begin{array}{l}\text { Miscel- } \\
\text { laneous }\end{array}$ & $\begin{array}{l}\text { No } \\
\text { diagnosis }\end{array}$ \\
\hline $\begin{array}{l}\text { Petersdorf } \\
1961^{1}\end{array}$ & USA & $U$ & $\begin{array}{l}1952- \\
1957\end{array}$ & $P$ & 100 & 36 & 19 & 19 & 29 & 7 \\
\hline $\begin{array}{l}\text { de Kleijn } \\
1995^{15}\end{array}$ & The Netherlands & $U$ & $\begin{array}{l}1988- \\
1992\end{array}$ & $\mathrm{R}$ & 53 & 21 & 19 & 23 & 8 & 30 \\
\hline $\begin{array}{l}\text { de Kleijn } \\
1997^{3}\end{array}$ & The Netherlands & $U$ & $\begin{array}{l}1992- \\
1994\end{array}$ & $P+M$ & 167 & 26 & 13 & 24 & 8 & 30 \\
\hline $\begin{array}{l}\text { Vanderschueren } \\
2003^{16}\end{array}$ & Belgium & $U$ & $\begin{array}{l}1990- \\
1999\end{array}$ & $\mathrm{P}$ & 185 & 11 & 10 & 18 & 8 & 53 \\
\hline $\begin{array}{l}\text { Efstathiou } \\
2010^{12}\end{array}$ & Greece & $U$ & $\begin{array}{l}1992- \\
2000\end{array}$ & $P$ & 112 & 30 & 11 & 33 & 5 & 21 \\
\hline $\begin{array}{l}\text { Tabak } \\
2004^{9}\end{array}$ & Turkey & U & $\begin{array}{l}1984- \\
2001\end{array}$ & $\mathrm{R}$ & 117 & 34 & 19 & 29 & 4 & 14 \\
\hline $\begin{array}{l}\text { Chin } \\
2006^{10}\end{array}$ & Taiwan & $U$ & $\begin{array}{l}2001- \\
2002\end{array}$ & $P$ & 94 & 57 & 9 & 7 & 9 & 18 \\
\hline $\begin{array}{l}\mathrm{Hu} \\
2008^{28}\end{array}$ & China & $U$ & $\begin{array}{l}2002- \\
2003\end{array}$ & $\mathrm{R}$ & 142 & 38 & 13 & 32 & 5 & 12 \\
\hline $\begin{array}{l}\text { Kucukardali } \\
2008^{11}\end{array}$ & Turkey & $U$ & $\begin{array}{l}2003- \\
2004\end{array}$ & $P+M$ & 154 & 34 & 14 & 31 & 5 & 16 \\
\hline $\begin{array}{l}\text { Zenone } \\
2006^{17}\end{array}$ & France & C & $\begin{array}{l}1999- \\
2005\end{array}$ & $P$ & 144 & 23 & 10 & 26 & 15 & 26 \\
\hline $\begin{array}{l}\text { Bleeker-Rovers } \\
2007^{5}\end{array}$ & The Netherlands & $U+C$ & $\begin{array}{l}2003- \\
2005\end{array}$ & $P+M$ & 73 & 16 & 7 & 22 & 4 & 51 \\
\hline $\begin{array}{l}\text { Hot } \\
2009^{19}\end{array}$ & France & U & $\begin{array}{l}1995- \\
2005\end{array}$ & $\mathrm{R}$ & 280 & 11 & 20 & 27 & 9 & 33 \\
\hline $\begin{array}{l}\text { Efstathiou } \\
2010^{12}\end{array}$ & Greece & $U$ & $\begin{array}{l}2001- \\
2007\end{array}$ & $\mathrm{P}$ & 100 & 35 & 10 & 36 & 3 & 16 \\
\hline $\begin{array}{l}\text { Bandyopadhyay } \\
2011^{13}\end{array}$ & India & $U$ & $\begin{array}{l}2008- \\
2009\end{array}$ & $\mathrm{P}$ & 164 & 55 & 22 & 11 & 0 & 12 \\
\hline $\begin{array}{l}\text { Mete } \\
2012^{14}\end{array}$ & Turkey & $U$ & $\begin{array}{l}2001- \\
2009\end{array}$ & $\mathrm{R}$ & 100 & 26 & 14 & 38 & 2 & 20 \\
\hline $\begin{array}{l}\text { Pedersen } \\
2012^{20}\end{array}$ & Denmark & $U$ & $\begin{array}{l}2005- \\
2010\end{array}$ & $\mathrm{R}$ & 52 & 19 & 8 & 33 & 0 & 40 \\
\hline $\begin{array}{l}\text { Vanderschueren } \\
2014^{21}\end{array}$ & Belgium & $U$ & $\begin{array}{l}2000- \\
2010\end{array}$ & $P$ & 436 & 17 & 11 & 24 & 10 & 39 \\
\hline $\begin{array}{l}\text { Naito } \\
2013^{18}\end{array}$ & Japan & $U+C$ & 2011 & $R+M$ & 121 & 23 & 11 & 31 & 12 & 23 \\
\hline
\end{tabular}

careful physical examination with specific attention to the eyes, temporal arteries, lymph nodes, liver and spleen, indicators of previous invasive procedures, and a complete examination of the skin and mucous membranes. Drug fever and factitious fever have to be excluded. Virtually all drugs can cause fever, even after long-term use. As they may mask PDCs, all antibiotics and 


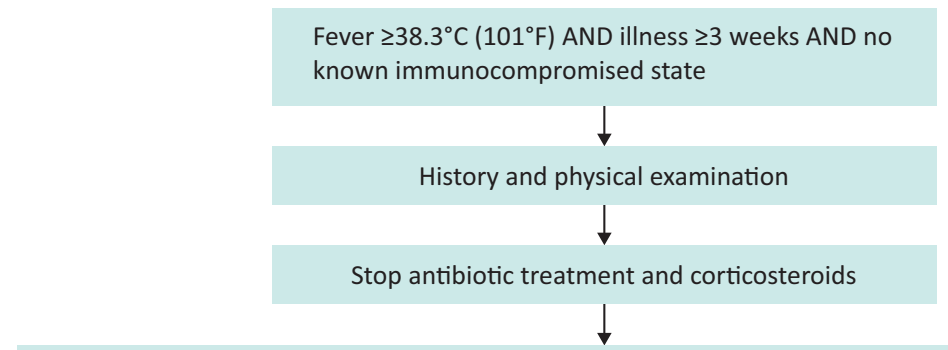

Obligatory investigations: ESR or CRP, haemoglobin, platelet count, leukocyte count and differentiation, electrolytes, creatinine, total protein, protein electrophoresis, alkaline phosphatase, ASAT, ALAT, LDH, creatine kinase, antinuclear antibodies, rheumatoid factor, urinalysis, blood cultures $(n=3)$, urine culture, chest X-ray, abdominal ultrasonography and tuberculin skin test

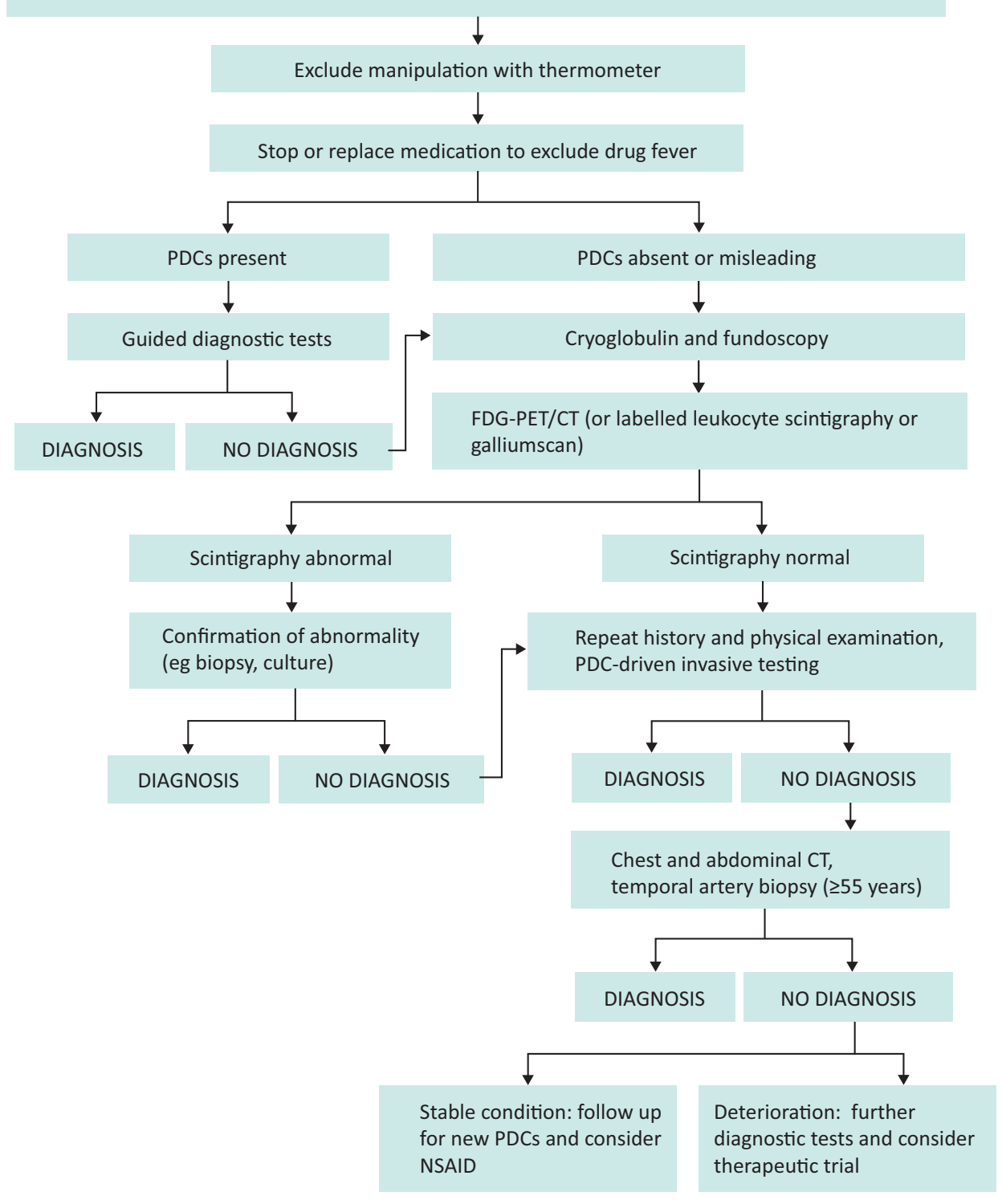

Fig 1. Flow chart of diagnosis of fever of unknown origin. ALT $=$ alanine transaminase; $\mathrm{AST}=$ aspartate aminotransferase; $\mathrm{CRP}=$ C-reactive protein; ESR = erythrocyte sedimentation rate; $\mathrm{LDH}=$ lactate dehydrogenase; NSAIDs = non-steroidal anti-inflammatory drugs; PDCs = potential diagnostic clues.

anti-inflammatory drugs have to be stopped at this stage. In virtually all cases, PDCs will be present. ${ }^{4,5}$ Further investigation should be guided by PDCs if present. Investigations should be selected based on local disease prevalence. In patients without
PDCs, random microbiologic serology has a low diagnostic yield and should therefore not be performed. ${ }^{3-5}$

When PDCs are absent or misleading, FUO should be further evaluated following a standard diagnostic protocol (Fig 1). 
Measurement of cryoglobulins and fundoscopic examination should be performed in an early stage, because of the frequent absence of typical symptoms in diseases that can be found by these investigations and their relatively low cost. ${ }^{4}$ When these tests do not lead to the final diagnosis, one should proceed to whole body imaging, ${ }^{6}$ preferably with ${ }^{18} \mathrm{FDG}-\mathrm{PET} / \mathrm{CT} .{ }^{23}$

\section{FDG-PET(/CT)}

FDG-PET is based on the increased uptake of FDG (fluorodeoxyglucose) by activated inflammatory cells, which occurs in infection, NIID and malignancy. In FUO, this nonspecificity is advantageous, as all of these may cause FUO. The role of FDG-PET(/CT) in FUO was recently reviewed. ${ }^{24}$ FDG-PET/CT is a non-invasive imaging technique with high diagnostic yield and should therefore be performed early in the investigation of FUO. FDG-PET was helpful in $40 \%$ and FDG-PET/CT in 54\% of cases. FDG-PET/CT is more specific, as it allows exact anatomical location of an FDG-positive lesion. Labeled leukocyte scintigraphy or gallium scintigraphy can be used as alternatives when FDG-PET/CT is unavailable, but have lower diagnostic yield. ${ }^{6,23,25}$

\section{$\mathrm{CT}$}

The diagnostic yield of CT alone is lower than the yield of FDGPET/CT. ${ }^{5}$ This is partly because specific anatomical changes may be absent in inflammation, particularly early in the illness, and CT cannot distinguish active infection from residual anatomical changes.

\section{Temporal artery biopsy}

The incidence of giant cell arteritis in FUO varies from $1 \%$ to over $10 \%$ in studies, and may become higher as our populations age. Temporal artery biopsy is considered a low-

\section{Key points}

In developing countries infections remain the most common cause of FUO, while non-infectious inflammatory diseases or no diagnosis cause FUO in the majority of patients in developed countries.

Potential diagnostic clues from history and physical examination should guide diagnostic procedures in FUO.

In the absence of potential diagnostic clues, a standardised diagnostic protocol with a major role for FDG-PET should be followed.

When no cause for the fever is found, antipyretics can be used as symptomatic treatment.

Most patients with FUO in whom no cause is identified show spontaneous remission of fever.

KEYWORDS: Fever of unknown origin, diagnosis, FDG-PET, infection, malignancy, connective tissue disease, systemic autoinflammatory diseases, treatment risk investigation, but false-negative results are often seen. ${ }^{26}$ FDG-PET/CT is a quick and non-invasive way to identify giant cell arteritis. ${ }^{26}$ When FDG-PET/CT is normal, temporal artery biopsy should be performed in elderly patients with FUO even in the absence of PDCs, as vasculitis limited to the temporal arteries may not be picked up by FDG-PET/CT due to the small vessel diameter and high FDG-uptake in the brain. ${ }^{5,25-27}$

\section{Bone marrow biopsy}

Although bone marrow aspiration can be diagnostic in some cases, ${ }^{19}$ it is considered only helpful in FUO with PDCs for a haematological disease or specific infection in the bone marrow. ${ }^{4,5}$ Bone marrow biopsy is preferred over aspiration, because of its higher diagnostic yield. PDC-guided investigation and the use of FDG-PET/CT early in the diagnostic workup of FUO will increase the diagnostic yield of bone marrow biopsy, as most bone marrow diseases that cause FUO will present with abnormalities at physical (eg lymphadenopathy, hepatosplenomegaly) or laboratory (eg cytopenia, elevated LDH) examination, or lead to abnormal FDG-PET/CT findings (in the case of lymphoma or metastatic tumours). ${ }^{5}$ Therefore, bone marrow biopsy should not be performed in the absence of PDCs for possible bone marrow diseases.

\section{Treatment}

When all previously described investigations do not lead to the diagnosis, further investigations should only be carried out when the patient deteriorates, or when new PDCs are identified by repeated history taking and physical examination. In stable patients without a diagnosis, non-steroidal anti-inflammatory drugs can be used as antipyretics.

When no cause for the fever is found and the patient deteriorates despite extensive investigation, a drug trial should be considered. Corticosteroids are an option, but they should not be prescribed too early, as important diagnostic clues can be altered or even disappear with steroid treatment, thereby delaying diagnosis and targeted specific therapy. In patients with a suspected autoinflammatory disorder the interleukin-1 receptor antagonist, anakinra, can be tried. Remission of symptoms is expected within $24-48$ hours. If anakinra is ineffective after two weeks of treatment, a beneficial effect should not be expected and the drug should be stopped.

\section{Prognosis}

The overall prognosis of FUO is determined by the underlying disease. In patients in whom no cause of FUO can be established, prognosis is generally good and mortality is low. ${ }^{21} \mathrm{Up}$ to $75 \%$ of patients experience spontaneous remission of fever, although this may take a long time. ${ }^{4,5,15,20}$ Treatment with NSAIDs or corticosteroids increases this proportion even further. ${ }^{5}$

\section{Conclusion}

More than 50 years after the first definition, FUO remains a challenging diagnostic problem. With the development of better diagnostic techniques, the cause of fever is often found before three weeks of illness and therefore only more difficult to diagnose cases meet the definition of FUO. The latest addition to the diagnostic protocol is early FDG-PET/CT, which has 
a high diagnostic yield. In a substantial part of all cases, no cause for the fever can be found. These patients have a good prognosis.

\section{References}

1 Petersdorf RG, Beeson PB. Fever of unexplained origin: report on 100 cases. Medicine (Baltimore) 1961;40:1-30.

2 Durack DT, Street AC. Fever of unknown origin - reexamined and redefined. Curr Clin Top Infect Dis 1991;11:35-51.

3 de Kleijn EM, Vandenbroucke JP, van der Meer JW. Fever of unknown origin (FUO). I A. prospective multicenter study of 167 patients with FUO, using fixed epidemiologic entry criteria. The Netherlands FUO Study Group. Medicine (Baltimore) 1997;76:392-400.

4 de Kleijn EM, van Lier HJ, van der Meer JW. Fever of unknown origin (FUO). II. Diagnostic procedures in a prospective multicenter study of 167 patients. The Netherlands FUO Study Group. Medicine (Baltimore) 1997;76:401-14.

5 Bleeker-Rovers CP, Vos FJ, de Kleijn EM et al. A prospective multicenter study on fever of unknown origin: the yield of a structured diagnostic protocol. Medicine (Baltimore) 2007;86:26-38.

6 Knockaert DC, Vanderschueren S, Blockmans D. Fever of unknown origin in adults: 40 years on. J Intern Med 2003;253:263-75.

7 Saltoglu N, Tasova Y, Midikli D et al. Fever of unknown origin in Turkey: evaluation of 87 cases during a nine-year-period of study. $J$ Infect 2004;48:81-5.

8 Ergonul O, Willke A, Azap A, Tekeli E. Revised definition of 'fever of unknown origin': limitations and opportunities. J Infect 2005;50:1-5.

9 Tabak F, Mert A, Celik AD et al. Fever of unknown origin in Turkey. Infection 2003;31:417-20.

10 Chin C, Chen YS, Lee SS et al. Fever of unknown origin in Taiwan. Infection 2006;34:75-80.

11 Kucukardali Y, Oncul O, Cavuslu S et al. The spectrum of diseases causing fever of unknown origin in Turkey: a multicenter study. Int J Infect Dis 2008;12:71-9.

12 Efstathiou SP, Pefanis AV, Tsiakou AG et al. Fever of unknown origin: discrimination between infectious and non-infectious causes. Eur J Intern Med 2010;21:137-43.

13 Bandyopadhyay D, Bandyopadhyay R, Paul R, Roy D. Etiological study of Fever of unknown origin in patients admitted to medicine ward of a teaching hospital of eastern India. J Glob Infect Dis 2011;3:329-33.

14 Mete B, Vanli E, Yemisen $\mathrm{M}$ et al. The role of invasive and noninvasive procedures in diagnosing fever of unknown origin. Int J Med Sci 2012;9:682-9.

15 de Kleijn EM, van der Meer JW. Fever of unknown origin (FUO): report on 53 patients in a Dutch university hospital. Neth J Med 1995;47:54-60.
16 Vanderschueren S, Knockaert D, Adriaenssens T et al. From prolonged febrile illness to fever of unknown origin: the challenge continues. Arch Intern Med 2003;163:1033-41.

17 Zenone T. Fever of unknown origin in adults: evaluation of 144 cases in a non-university hospital. Scand J Infect Dis 2006;38:632-8.

18 Naito T, Mizooka M, Mitsumoto F et al. Diagnostic workup for fever of unknown origin: a multicenter collaborative retrospective study. BMJ Open 2013;3:e003971.

19 Hot A, Jaisson I, Girard C et al. Yield of bone marrow examination in diagnosing the source of fever of unknown origin. Arch Intern Med 2009;169:2018-23.

20 Pedersen TI, Roed C, Knudsen LS et al. Fever of unknown origin: a retrospective study of 52 cases with evaluation of the diagnostic utility of FDG-PET/CT. Scand J Infect Dis 2012;44:18-23.

21 Vanderschueren S, Eyckmans T, De Munter P, Knockaert D. Mortality in patients presenting with fever of unknown origin. Acta Clin Belg 2014;69:12-6.

22 Gaeta GB, Fusco FM, Nardiello S. Fever of unknown origin: a systematic review of the literature for 1995-2004. Nucl Med Commun 2006;27:205-11.

23 Bleeker-Rovers CP, Vos FJ, Mudde AH et al. A prospective multicentre study of the value of FDG-PET as part of a structured diagnostic protocol in patients with fever of unknown origin. Eur J Nucl Med Mol Imaging 2007;34:694-703.

24 Kouijzer IJ, Bleeker-Rovers CP, Oyen WJ. FDG-PET in fever of unknown origin. Semin Nucl Med 2013;43:333-9.

25 Mourad O, Palda V, Detsky AS. A comprehensive evidence-based approach to fever of unknown origin. Arch Intern Med 2003;163:545-51.

26 Besson FL, Parienti JJ, Bienvenu B et al. Diagnostic performance of (1)(8)F-fluorodeoxyglucose positron emission tomography in giant cell arteritis: a systematic review and meta-analysis. Eur J Nucl Med Mol Imaging 2011;38:1764-72.

27 Bleeker-Rovers CP, Bredie SJ, van der Meer JW et al. F-18fluorodeoxyglucose positron emission tomography in diagnosis and follow-up of patients with different types of vasculitis. Neth J Med 2003;61:323-9.

$28 \mathrm{Hu}$ Y, Lu H, Zhang Y et al. Fever of unknown origin: revisit of 142 cases in a tertiary Chinese hospital. Biosci Trends 2008;2:44-6.

Address for correspondence: Dr CM Mulders-Manders, Radboud University Medical Center, Department of Internal Medicine, 463 PO Box 91016500 HB Nijmegen, The Netherlands

Email: karin.mulders-manders@radboudumc.nl 